\title{
The Impact of Oxygen on the Properties of
}

\section{$\mathrm{Cu}_{3} \mathrm{~N}$ and $\mathrm{Cu}_{3-\mathrm{x}} \mathrm{N}_{1-\mathrm{x}} \mathrm{O}_{\mathrm{x}}$}

Matthew Zervos, * Andreas Othonos $§$, Theodore Pavloudis $\square$, Stefanos Giaremis $\square$, Joseph

Kioseoglou $\square$, Kalliopi Mavridou $\square$, Maria Katsikini $\square$, Fani Pinakidou $\square$ and Eleni C. Paloura

* Nanostructured Materials and Devices Laboratory, School of Engineering, University of Cyprus, PO Box 20537, Nicosia, 1678, Cyprus.

$\S^{\S}$ Laboratory of Ultrafast Science, Department of Physics, University of Cyprus, PO Box 20537, Nicosia, 1678, Cyprus

Department of Physics, Aristotle University of Thessaloniki, GR-54124, Thessaloniki, Greece.

*e-mail: zervos@ucy.ac.cy 


\section{Supporting Information}

\section{S1. Computational Methods}

The DFT $+\mathrm{U}$ method was employed to properly describe the behavior of $d$ electrons via the simplified, rotationally invariant approach introduced by Dudarev et al ${ }^{1}$. The $+\mathrm{U}$ potential was applied only to the $d$ electrons of $\mathrm{Cu}$ and was set at $7.64 \mathrm{eV}$ which has been found to reproduce accurately the bandgap of $\mathrm{Cu}_{3} \mathrm{~N}$ predicted by range separated Heyd -Scuseria - Ernzerhof (HSE) hybrid functionals with only a minor difference $(\sim 0.5 \%)$ in the lattice constant ${ }^{2}$. Non-spherical contributions, related to the gradient of the density in the PAW spheres, were included to the total energy. The energy cut-off of the plane-wave basis set was $520 \mathrm{eV}$. A Gaussian smearing with a width of $0.01 \mathrm{eV}$ was chosen for the partial occupancies of the electronic orbitals.

For the $\mathrm{O}$ defect calculations, we used $5 \times 5 \times 5$ supercells comprising 500 atoms, while for $\mathrm{Cu} / \mathrm{N}$ vacancy- $\mathrm{O}_{\mathrm{N}}$ defect pair calculations we used $3 \times 3 \times 3$ supercells comprising 108 atoms for a 3.7 at. $\% \mathrm{O}$ concentration. For the phonon calculations we used $4 \times 4 \times 4$ supercells comprising 256 atoms. The Brillouin zones were sampled using $2 \times 2 \times 2 \Gamma$ centred $k$-point meshes for all the sets of supercell calculations. А $\Gamma$ - centred $16 \times 16 \mathrm{x}$ $16 k$-point mesh was used for the unit cells for the calculation of the Born effective charges required for finding the infra-red (IR) and Raman spectra. The defect formation energies were calculated according to the methodology described by Freysoldt et al. ${ }^{3}$ $\mathrm{Cu}$-rich conditions were assumed, hence the chemical potential of $\mathrm{Cu}$ was $\mu_{C u}=$ $E_{C u, b u l k}$ and the chemical potentials of $\mathrm{N}$ and $\mathrm{O}$ were calculated by $\mu_{N}=E_{C u_{3} N, b u l k}-$

$\mu_{C u}$ and $\mu_{O}=E_{C u_{2} O, b u l k}-\mu_{C u}$. The phonon and vibrational spectra calculations were 
performed with Phonopy ${ }^{4}$ with VASP as the force calculator. ${ }^{5}$ Raman calculations were performed with the Phonopy - Spectroscopy package. ${ }^{6}$ The tolerance for the electronic and ionic steps was set at $10^{-8} \mathrm{eV}$ and the projection operators were evaluated in reciprocal space with an additional support grid that was used for the evaluation of the augmentation charges. The phonon density of states (DOS) and partial phonon DOS were calculated with the linear tetrahedron method using $128 \times 128 \times 128$ and $64 \times 64$ x $64 \Gamma$-centred $q$-point meshes respectively.

\section{S2. X-Ray Absorption Fine Structure}

The $\mathrm{Cu}-\mathrm{K}$-XAFS measurements were conducted at the KMC2 beamline at the storage ring facility BESSY II $^{7}$ at nearly grazing incidence $\left(10^{\circ}\right)$. The spectra were recorded in the fluorescence yield mode using an energy dispersive detector (XFlash, Bruker, Germany); an ionization chamber was used to record spectra of $\mathrm{Cu}$ powder compounds $\left(\mathrm{CuO}, \mathrm{Cu}_{2} \mathrm{O}\right)$ and $\mathrm{Cu}$-foil in the transmission geometry for reference purposes. The $\mathrm{X}$ Ray Absorption Near Edge Structure (XANES) spectra were normalized with the intensity of the impinging beam recorded with and an ionization chamber, positioned prior to the sample. The analysis of the Extended X-Ray Absorption Fine Structure (EXAFS) spectra proceeded after subtraction of the atomic background, ${ }^{8}$ construction of the theoretical phase and amplitude functions for the scattering paths while curve fitting was carried out in both $R$ - and $k$-space. 


\begin{tabular}{|c|c|c|c|}
\hline Shell & $\mathrm{CN}, \mathrm{R}, \sigma^{2}$ & $300^{\circ} \mathrm{C}$ & $500^{\circ} \mathrm{C}$ \\
\hline \multirow[t]{3}{*}{$1^{\text {st }} \mathrm{nn}$} & $\mathrm{CN}( \pm 10 \%)$ & 1.8 & 1.7 \\
\hline & $\mathrm{R}(\AA)( \pm 0.01)$ & 1.90 & 1.90 \\
\hline & $\sigma^{2}\left(\times 10^{-3} \AA^{2}\right)( \pm 10 \%)$ & 3.4 & 2.9 \\
\hline \multirow[t]{3}{*}{$2^{\text {nd }} n n$} & $\mathrm{CN}( \pm 20 \%)$ & 6.5 & 8.2 \\
\hline & $\mathrm{R}(\AA)( \pm 0.02)$ & 2.70 & 2.70 \\
\hline & $\sigma^{2}\left(\times 10^{-3} \AA^{2}\right)( \pm 15 \%)$ & 11.4 & 11.6 \\
\hline \multirow[t]{3}{*}{$3^{\text {rd }} \mathrm{nn}(\mathrm{ms})$} & $\mathrm{CN}$ & $7.2^{*}$ & $6.8^{*}$ \\
\hline & $\mathrm{R}(\AA)$ & $3.26^{*}$ & $3.26^{*}$ \\
\hline & $\sigma^{2}\left(\times 10^{-3} \AA^{2}\right)( \pm 15 \%)$ & 3.1 & 3.7 \\
\hline \multirow[t]{3}{*}{$4^{\text {th }} \mathrm{nn}$} & $\mathrm{CN}( \pm 25 \%)$ & 5.8 & 5.2 \\
\hline & $\mathrm{R}(\AA)( \pm 0.03)$ & 3.70 & 3.67 \\
\hline & $\sigma^{2}\left(\times 10^{-3} \AA^{2}\right)$ & $11.4^{*}$ & $11.6^{*}$ \\
\hline \multirow[t]{3}{*}{$5^{\text {th }} \mathrm{nn}(\mathrm{ms})$} & $\mathrm{CN}$ & $3.6^{*}$ & $3.4^{*}$ \\
\hline & $\mathrm{R}(\AA)$ & $3.82 *$ & $3.82 *$ \\
\hline & $\sigma^{2}\left(\times 10^{-3} \AA^{2}\right)$ & $6.1^{*}$ & $7.4^{*}$ \\
\hline \multirow[t]{3}{*}{$6^{\text {th }} \mathrm{nn}$} & $\mathrm{CN}( \pm 30 \%)$ & 4.3 & 6.4 \\
\hline & $\mathrm{R}(\AA)( \pm 0.04)$ & 4.24 & 4.26 \\
\hline & $\sigma^{2}\left(\times 10^{-3} \AA^{2}\right)( \pm 20 \%)$ & 7.6 & 1.5 \\
\hline
\end{tabular}

Table S1: $\mathrm{Cu}-\mathrm{K}-\mathrm{EXAFS}$ results from the $\mathrm{Cu}_{3} \mathrm{~N}$ grown on $\mathrm{Si} . \mathrm{CN}$ stands for the coordination number, $R$ is the interatomic distance and $\sigma^{2}$ is the Debye-Waller factor in each nearest neighbor (nn) shell; ms stands for multiple scattering. The asterisk $\left({ }^{*}\right)$ denotes parameter values that were kept fixed during the fitting process. 
The stoichiometry of the films can be addressed using EXAFS measurements at the $\mathrm{Cu}$ $K$-edge, in terms of undercoordination of the $\mathrm{Cu}$ atoms and the presence of $\mathrm{N}_{2}$ voids. This is the case of two films processed at temperatures similar to those of the sputtered films. More specifically, the EXAFS analysis results from two $\mathrm{Cu}_{3} \mathrm{~N}$ films deposited on $\mathrm{Si}$ and annealed at 400 and $500{ }^{\circ} \mathrm{C}$ under $\mathrm{NH}_{3}: \mathrm{O}_{2}$, demonstrate that the number of $\mathrm{N}$ atoms bonded with $\mathrm{Cu}$ in the $1^{\text {st }}$ nearest neighbor (nn) shell differs. The results are listed in the Table S2 and Figure S1 shows the Fourier Transforms of the raw and fitted $\mathrm{k}^{3} \times \chi(\mathrm{k}) \mathrm{Cu}-K$-EXAFS spectra. The largest fraction of $\mathrm{N}_{2}$ voids $(40 \%)$ is identified in the films annealed at the lowest temperature. In contrast, the percentage of voids reduces to $25 \%$ upon annealing at $500^{\circ} \mathrm{C}$. No major structural modifications are detected in the next nn shells.

\begin{tabular}{|l|l|}
\hline Annealing $\mathbf{T}$ & \% of $\mathbf{N}_{\mathbf{2}}$ voids \\
\hline $\mathbf{4 0 0}{ }^{\circ} \mathbf{C}$ & $40 \pm 4 \%$ \\
\hline $500^{\circ} \mathbf{C}$ & $25 \pm 3 \%$ \\
\hline
\end{tabular}

Table S2 


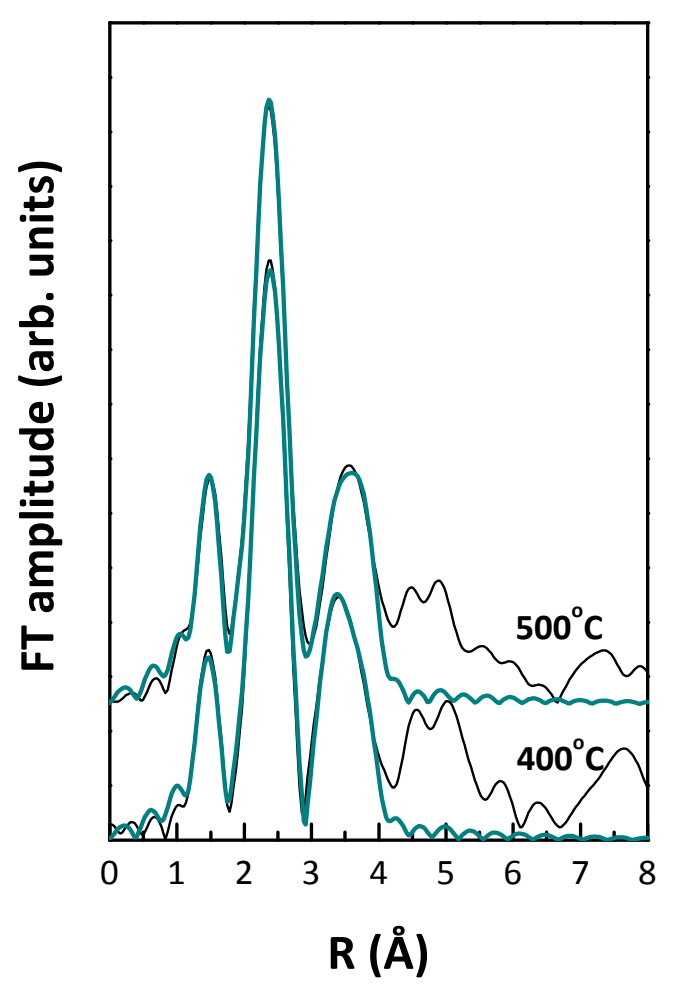

Figure S1 Fourier Transforms (FT) of the $\mathrm{k}^{3} \times \chi(\mathrm{k}) \mathrm{Cu}-K$-EXAFS spectra of two films annealed at 400 and $500^{\circ} \mathrm{C}$, respectively; the experimental data and the fitting curve are shown in black and colored lines, respectively.

\section{S3. Structural Properties of Defects}

The impact of different kinds of oxygen substitutional defects, with or without $\mathrm{Cu}$ vacancies, was investigated further by performing $a b$ initio calculations of the bond lengths and phonon properties for the cases where a $\mathrm{Cu}$ or a $\mathrm{N}$ vacancy occurs simultaneously with an $\mathrm{O}$ atom on a $\mathrm{N}$ site i.e. $\mathrm{O}_{\mathrm{N}}$ defect.

More specifically we considered two cases. In the first case, a $\mathrm{Cu}$ atom was removed from a second, nearest neighbor lattice site with respect to the $\mathrm{O}$ atom, resulting in a $\mathrm{V}_{\mathrm{Cu}}$ as shown in Figure $\mathrm{S} 2(\mathrm{a})$. In the second case, a $\mathrm{N}$ atom was removed from a nearest neighbor site with respect to the $\mathrm{O}$ atom, resulting in a $V_{N}$, as shown in Figure $S 2(b)$. 
The relaxed structures for the two aforementioned cases are shown in Figures S2(c) and (d) respectively.

In the first case of $\mathrm{V}_{\mathrm{Cu}}$, the $\mathrm{Cu}-\mathrm{O}$ bond length appears to be shorter along the direction of the vacancy and longer along the perpendicular direction. The $\mathrm{Cu}-\mathrm{O}$ bond in both of these directions is shorter than in the case of $\mathrm{Cu}_{3} \mathrm{~N}$ without vacancies i.e. $1.953 \AA$, in which the $\mathrm{Cu}-\mathrm{O}$ bond is always longer than the $\mathrm{Cu}-\mathrm{N}$ bonds. The vicinity of the $\mathrm{V}_{\mathrm{Cu}}$ is then under tensile strain along the $\mathrm{V}_{\mathrm{Cu}}-\mathrm{O}$ direction and the vicinity of $\mathrm{V}_{\mathrm{N}}$ is under compressive strain along the $\mathrm{V}_{\mathrm{N}}-\mathrm{O}$ direction.
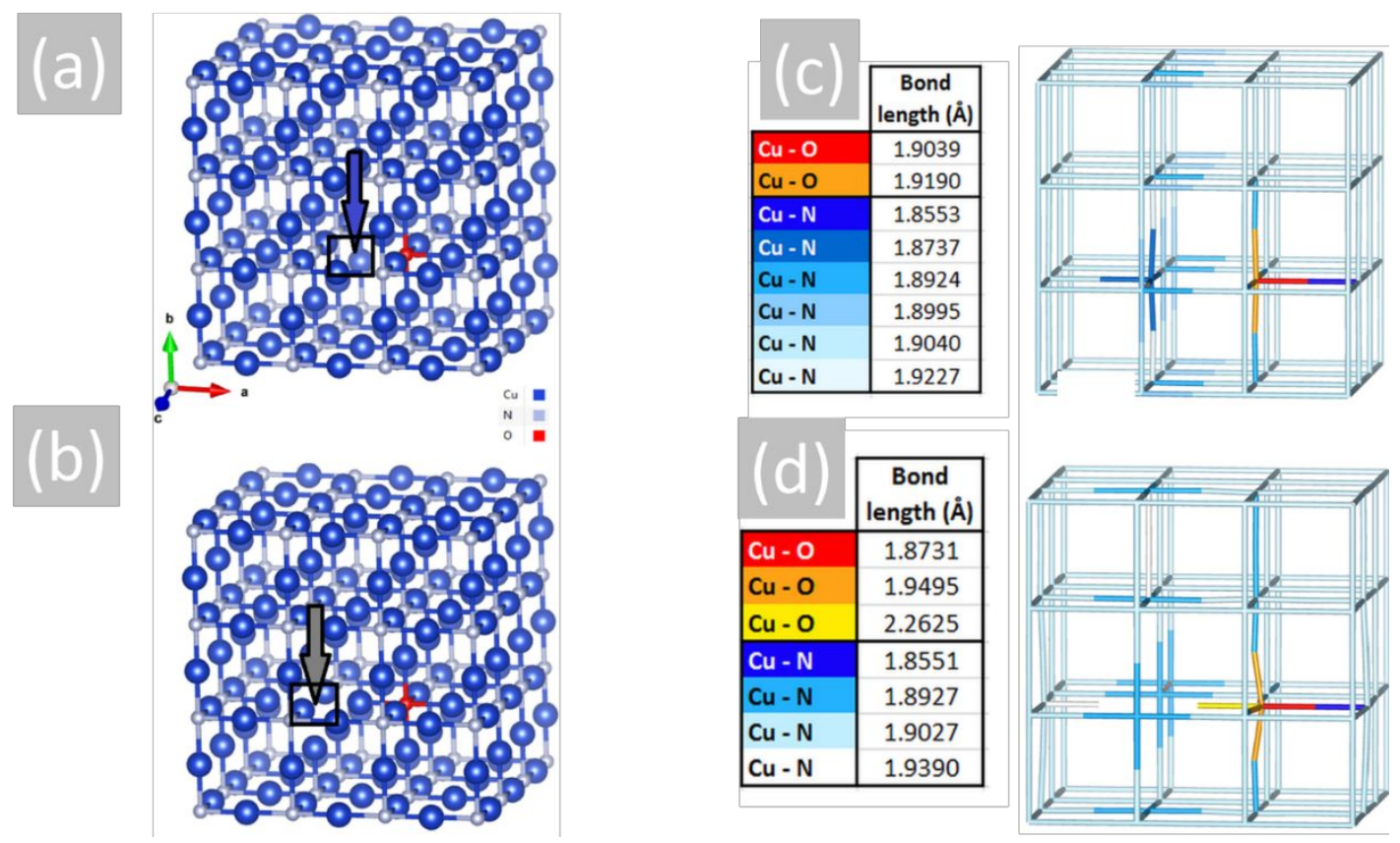

Figure S2 (a), (b) Structural models for the cases of $\mathrm{O}: \mathrm{Cu}_{3} \mathrm{~N}$ with a $\mathrm{Cu}$ and $\mathrm{N}$ vacancy, respectively; the sites of the $\mathrm{Cu}$ and $\mathrm{N}$ vacancies are denoted with blue and grey arrows, respectively (c), (d) colored representation of the different values of the $\mathrm{Cu}-\mathrm{O}$ and $\mathrm{Cu}$ $-\mathrm{N}$ bond lengths for the cases of $\mathrm{O}: \mathrm{Cu}_{3} \mathrm{~N}$ with a $\mathrm{Cu}$ and $\mathrm{N}$ vacancy, respectively. 


\section{S4. References}

(1) Dudarev, S. L.; Botton, G. A.; Savrasov, S. Y.; Humphreys, C.J.; Sutton, A.P. Electron-Energy-Loss Spectra and the Structural Stability of Nickel Oxide: An LSDA+U study. Phys. Rev. B 1995, 57, 1505.

(2) Krukau, A. V.; Vydrov, O. A; Izmaylov, A. F.; Scuseria, G. E. Influence of the Exchange Screening Parameter on the Performance of Screened Hybrid Functionals. $J$. Chem. Phys. 2006, 125, 224106.

(3) Freysoldt, C.; Grabowski, B.; Hickel, T.; Neugebauer, J. First-Principles Calculations for Point Defects in Solids. Rev. Mod. Phys. 2014, 86, 253-304.

(4) Togo, A.; Tanaka, I. First Principles Phonon Calculations in Materials Science. Scr. Mater. 2015, 108, 1-5.

(5) Kresse, G.; Furthmüller, G. Efficient Iterative Schemes for Ab Initio Total-Energy Calculations Using a Plane-Wave Basis Set. Phys. Rev. B. 1996, 54, 11169.

(6) Skelton, J. M.; Burton, L. A.; Jackson, A. J.; Oba, F.; Parker, S. C.; Walsh, A. Lattice Dynamics of the Tin Sulphides $\mathrm{SnS}_{2}, \mathrm{SnS}$ and $\mathrm{Sn}_{2} \mathrm{~S}_{3}$ : vibrational spectra and thermal transport. Phys. Chem. Chem. Phys. 2017, 19, 12452.

(7) Többens, D.M.; Zander, S. KMC-2: An X-ray Beamline with Dedicated Diffraction and XAS End-Stations at BESSY II, J. Large-Scale Res. Fac. 2016, 49, 2.

(8) Ravel, J.B.; Newville, M; ATHENA, ARTEMIS, HEPHAESTUS: Data Analysis for X-ray Absorption Spectroscopy Using IFEFFIT, J. Synchrotron. Rad. 2005, 12, $537-541$. 